\title{
Amorphous silica nanoparticles impair vascular homeostasis and induce systemic inflammation
}

\author{
This article was published in the following Dove Press journal: \\ International Journal of Nanomedicine \\ 2 June 2014 \\ Number of times this article has been viewed
}

\begin{abstract}
Abderrahim Nemmar'
Sulayma Albarwani ${ }^{2}$

Sumaya Beegam'

Priya Yuvaraju'

Javed Yasin ${ }^{3}$

Samir Attoub ${ }^{4}$

Badreldin $\mathrm{H} \mathrm{Ali}^{5}$

'Department of Physiology, College of Medicine and Health Sciences, United Arab Emirates University, Al Ain, United Arab Emirates; ${ }^{2}$ Department of Physiology, College of Medicine and Health Sciences, Sultan Qaboos University, Al-Khod, Sultanate of Oman; ${ }^{3}$ Department of Internal Medicine, College of Medicine and Health Sciences, United Arab Emirates University, Al Ain, United Arab Emirates; ${ }^{4}$ Department of Pharmacology, College of Medicine and Health Sciences, United Arab Emirates University, Al Ain, United Arab Emirates; ${ }^{5}$ Department of Pharmacology, College of Medicine and Health Sciences, Sultan Qaboos University, Al-Khod, Sultanate of Oman
\end{abstract}

\begin{abstract}
Amorphous silica nanoparticles (SiNPs) are being used in biomedical, pharmaceutical, and many other industrial applications entailing human exposure. However, their potential vascular and systemic pathophysiologic effects are not fully understood. Here, we investigated the acute ( 24 hours) systemic toxicity of intraperitoneally administered $50 \mathrm{~nm}$ and $500 \mathrm{~nm}$ SiNPs in mice $(0.5 \mathrm{mg} / \mathrm{kg})$. Both sizes of SiNPs induced a platelet proaggregatory effect in pial venules and increased plasma concentration of plasminogen activator inhibitor-1. Elevated plasma levels of von Willebrand factor and fibrinogen and a decrease in the number of circulating platelets were only seen following the administration of $50 \mathrm{~nm}$ SiNPs. The direct addition of SiNPs to untreated mouse blood significantly induced in vitro platelet aggregation in a dose-dependent fashion, and these effects were more pronounced with $50 \mathrm{~nm}$ SiNPs. Both sizes of SiNPs increased lactate dehydrogenase activity and interleukin $1 \beta$ concentration. However, tumor necrosis factor $\alpha$ concentration was only increased after the administration of $50 \mathrm{~nm}$ SiNPs. Nevertheless, plasma markers of oxidative stress, including 8-isoprostane, thiobarbituric acid reactive substances, catalase, and glutathione S-transferase, were not affected by SiNPs. The in vitro exposure of human umbilical vein endothelial cells to SiNPs showed a reduced cellular viability, and more potency was seen with $50 \mathrm{~nm}$ SiNPs. Both sizes of SiNPs caused a decrease in endothelium-dependent relaxation of isolated small mesenteric arteries. We conclude that amorphous SiNPs cause systemic inflammation and coagulation events, and alter vascular reactivity. Overall, the effects observed with $50 \mathrm{~nm}$ SiNPs were more pronounced than those with $500 \mathrm{~nm}$ SiNPs. These findings provide new insight into the deleterious effect of amorphous SiNPs on vascular homeostasis.
\end{abstract}

Keywords: amorphous silica nanoparticles, thrombosis, toxicity, systemic inflammation

\section{Introduction}

Silicon dioxide exists in either crystalline or amorphous forms. ${ }^{1}$ It is well established that occupational inhalation exposure to crystalline silica causes silicosis, which can progress even after the end of occupational exposure. An association of crystalline silica exposure and silicosis, as well as lung cancer, chronic obstructive pulmonary disease, and pulmonary tuberculosis, have been recently reported. ${ }^{2}$ The development of nanotechnology has raised new interest in the use of amorphous silica in biomedical, pharmaceutical, and many other industrial applications. Amorphous silica nanoparticles (SiNPs) are being applied increasingly in industrial manufacturing, high-molecule composite materials, cosmetics, and foodstuffs. ${ }^{1}$ Moreover, SiNPs are being developed for a host of biomedical and pharmaceutical applications such as drug delivery, cancer therapy, imaging probes, biosensors, and enzyme immobilization. ${ }^{1}$

Accidental contact during production or use of nanoparticles is likely to happen via different routes such as skin penetration, ingestion, or inhalation. ${ }^{3,4}$ Even after inhalation, nanoparticles have been reported to rapidly translocate to
Correspondence:Abderrahim Nemmar Department of Physiology, College of Medicine and Health Sciences, United Arab Emirates University, PO Box 17666, Al Ain, United Arab Emirates Tel +97I 37137533

Fax +97I 37671966

Email anemmar@uaeu.ac.ae 
the systemic circulation and reach different organs. ${ }^{5-8}$ Moreover, with medical applications, injected nanoparticles can be distributed by the bloodstream and affect vascular homeostasis. ${ }^{1}$ Therefore, studies on the effects of nanoparticles on vascular homeostasis are relevant and much needed.

There is a growing body of evidence that amorphous SiNPs can cause toxic and inflammatory effects due to their unique physicochemical profile. A concentration-dependent cytotoxicity of SiNPs on endothelial cell line EA.hy926, epithelial cell line A549, and monocyte-macrophages J774 has been previously reported. ${ }^{9}{ }^{910}$ SiNPs have been reported to induce cytotoxicity and inflammatory responses in vitro in a co-culture model of the alveolar-capillary barrier. ${ }^{11}$ There is evidence that SiNPs can induce impairment of proliferative activity and proinflammatory stimulation of endothelial cells in vitro. ${ }^{12}$ Exposure to SiNPs induces protein expression of the adhesion molecules intercellular adhesion molecule 1 and vascular cell adhesion molecule $1 .{ }^{13}$ Moreover, Corbalan et $\mathrm{al}^{14}$ demonstrated that SiNPs penetrate the plasma membrane of endothelial cells and stimulate nitric oxide release in vitro. Subsequently, the same group has shown that exposure of human platelets in vitro to amorphous SiNPs induces a low $[\mathrm{NO}] /\left[\mathrm{ONOO}^{-}\right]$ratio leading to platelet aggregation. ${ }^{15}$ A study reported that SiNPs can significantly augment proinflammatory and procoagulant responses through CD40CD40L-mediated monocyte-endothelial cell interactions, which suggests that cooperative interactions between SiNPs, endothelial cells, and monocytes may trigger cardiovascular dysfunction such as atherosclerosis and thrombosis. ${ }^{16}$ It has been demonstrated that intratracheally instilled SiNPs are able to cross the alveolar-capillary barrier and cause systemic effects. ${ }^{17}$ We have previously demonstrated that pulmonary exposure to crystalline silica activates circulating platelets and enhances peripheral thrombosis in hamsters. ${ }^{18}$ However, the possible effects of amorphous SiNPs on thrombosis in vivo and its link to systemic inflammation have not, as far as we are aware, been reported.

In the present study, we assessed the in vivo size $(50 \mathrm{~nm}$ and $500 \mathrm{~nm})$ effects of SiNPs $(0.5 \mathrm{mg} / \mathrm{kg})$ on a comprehensive set of indices related to vascular homeostasis, including in vivo thrombosis in pial venules in mice and systemic markers of inflammation, oxidative stress, and fibrinolysis. Moreover, the in vitro dose-effects of SiNPs were also assessed on mouse platelet aggregation, cell viability in human umbilical vein endothelial cells (HUVEC), and endothelium-dependent relaxation of isolated small mesenteric arteries of rats.

\section{Materials and methods Amorphous SiNPs}

Amorphous SiNPs of two different sizes (50 nm and $500 \mathrm{~nm}$ ) were purchased from Polysciences, Inc. (Warrington, PA, USA). Their structure, shape, size, and charge were recently analyzed. ${ }^{14,15}$

\section{Animals and intraperitoneal administration of amorphous SiNPs}

This project was reviewed and approved by our Institutional Review Board and experiments were performed in accordance with protocols approved by the Institutional Animal Care and Research Advisory Committee.

SiNPs were suspended in normal saline $(\mathrm{NaCl} 0.9 \%)$ containing Tween $80(0.01 \%)$. To minimize aggregation, particle suspensions were always sonicated (Clifton Ultrasonic Bath; Clifton, NJ, USA) for 15 minutes and vortexed before their dilution and prior to intraperitoneal (IP) administration.

Male Tuck-Ordinary mice (HsdOla:TO; Harlan Laboratories UK, Ltd., Bicester, UK) were housed in light (12 h light:12 h dark cycle) and temperature-controlled $\left(22^{\circ} \mathrm{C} \pm 1^{\circ} \mathrm{C}\right)$ rooms. They had free access to commercial laboratory chow and were provided tap water ad libitum.

Either SiNP suspensions $(0.5 \mathrm{mg} / \mathrm{kg})$ or saline-only were intraperitoneally injected $(150 \mu \mathrm{L})$, and 24 hours later various thrombotic and systemic parameters were assessed.

\section{Blood collection and analysis}

Twenty-four hours after the IP administration of either saline or SiNPs, the animals were anesthetized intraperitoneally with sodium pentobarbital $(45 \mathrm{mg} / \mathrm{kg}$ ) and blood was drawn from the inferior vena cava in ethylenediaminetetraacetic acid (4\%). A sample was used for platelet counting using an ABX VET ABC hematology analyzer with a mouse card (HORIBA ABX SAS, Montpellier, France). The remaining blood was centrifuged at $4^{\circ} \mathrm{C}$ for 15 minutes at $900 \mathrm{~g}$ and the plasma samples were stored at $-80^{\circ} \mathrm{C}$ until further analysis.

\section{Experimental pial venular thrombosis model}

In a separate experiment, in vivo pial venular thrombogenesis was assessed 24 hours after the IP administration of either SiNPs or saline, according to a previously described technique. ${ }^{19,20}$ Briefly, the trachea was intubated after induction of anesthesia with urethane (1 mg/g body weight, IP), and a $2 \mathrm{~F}$ venous catheter (Sims Portex Ltd., Hythe, Kent, UK) was inserted in the right jugular vein for the administration of fluorescein (Sigma-Aldrich Co., 
St Louis, MO, USA). After that, a craniotomy was first performed on the left side, using a microdrill, and the dura was stripped open. Only untraumatized preparations were used, and those showing trauma to either microvessels or underlying brain tissue were discarded. The animals were then placed on the stage of a fluorescence microscope (Olympus America Inc., Melville, NY, USA) attached to a camera and DVD recorder. A heating mat was placed under the mice and body temperature was raised to $37^{\circ} \mathrm{C}$, as monitored by a rectal thermoprobe connected to a temperature reader (Physitemp Instruments Inc., Clifton, NJ, USA). The cranial preparation was moistened continuously with artificial cerebrospinal fluid of the following composition (mM): $\mathrm{NaCl} 124, \mathrm{KCl} 5, \mathrm{NaH}_{2} \mathrm{PO}_{4} 3, \mathrm{CaCl}_{2} 2.5, \mathrm{MgSO}_{4} \cdot 4$, $\mathrm{NaHCO}_{3} 23$ and glucose 10, $\mathrm{pH}$ 7.3-7.4. A field containing venules $15-20 \mu \mathrm{m}$ in diameter was chosen. Such a field was taped prior to and during the photochemical insult, which was carried out by injecting fluorescein $(0.1 \mathrm{~mL} / \mathrm{mouse}$ of $5 \%$ solution) via the jugular vein, which was allowed to circulate for 30-40 seconds. The cranial preparation was then exposed to stabilized mercury light. The combination produces endothelium injury of the venules. This, in turn, causes platelets to adhere at the site of endothelial damage and then aggregate. Platelets aggregate and the thrombus formation grows in size until complete vascular occlusion. The time from the photochemical injury until full vascular occlusion (time to flow stop) in venules was measured in seconds. At the end of the experiments, the animals were euthanized by an overdose of urethane.

\section{Determination of systemic markers of inflammation, oxidative stress, and fibrinolysis}

The concentrations of plasminogen activator inhibitor-1 (PAI-1) (Molecular Innovations, Novi, MI, USA), fibrinogen (Molecular Innovations), von Willebrand factor (vWF) (Uscn Life Science Inc., Wuhan, People's Republic of China), tumor necrosis factor $\alpha(\mathrm{TNF} \alpha)$ (R \& D Systems, Minneapolis, MN, USA), interleukin $1 \beta$ (IL-1 $\beta$ ) (R \& D Systems), and 8-isoprostane (Cayman Chemical Company, Ann Arbor, MI, USA) were determined using enzyme-linked immunosorbent assay kits. The levels of thiobarbituric acid reactive substances (TBARS), catalase, and glutathione S-transferase (GST) were measured using kits obtained from Cayman Chemical Company. The lactate dehydrogenase (LDH) activity was measured using standard laboratory methods with an LX20 multiple automated analyzer (Beckman Coulter, Inc., Brea, CA, USA).

\section{In vitro measurement of prothrombin time and activated partial thromboplastin time}

Following saline or SiNP administration, blood was withdrawn from each mouse, as described above. The prothrombin time (PT) was measured ${ }^{21-23}$ on freshly collected, platelet-poor plasma with human relipidated recombinant thromboplastin (RecombiPlasTin; Instrumentation Laboratory, Orangeburg, NY, USA) in combination with a Merlin coagulometer (MC 1 VET; Merlin Medical, Lemgo, Germany)]. Activated partial thromboplastin time (aPTT) was measure ${ }^{21-23}$ with automated aPTT reagent (bioMerieux, Inc., Durham, NC, USA) using a Merlin coagulometer (MC 1 VET; Merlin Medical). Normal plasma used as reference for both the PT and aPTT was prepared by pooling equal portions of platelet-poor plasmas from the blood of six untreated mice.

\section{Platelet aggregation in mouse whole blood in vitro}

The platelet aggregation assay in whole blood was performed, with slight modification, as described before. ${ }^{24}$ After anesthesia, blood from untreated mice was withdrawn from the inferior vena cava and placed in citrate $(3.2 \%)$, and $100 \mu \mathrm{L}$ aliquots were added to the well of a Merlin coagulometer (MC 1 VET; Merlin Medical). The blood samples were incubated at $37.2^{\circ} \mathrm{C}$ with either saline (control) or SiNPs $(0.2-5 \mu \mathrm{g} / \mathrm{mL})$ for 3 minutes, and then stirred for another 3 minutes. At the end of this period, $25 \mu \mathrm{L}$ samples were removed and fixed on ice in $225 \mathrm{~mL}$ CellFIX ${ }^{\mathrm{TM}}$ (BD Biosciences, San Jose, CA, USA). After fixation, single platelets were counted in a VET ABX Micros with mouse card (HORIBA ABX SAS). The degree of platelet aggregation following SiNP exposure was expressed as a percentage of control (saline-treated blood).

\section{HUVEC cellular viability}

HUVEC (EMD Millipore, Billerica, MA, USA) were maintained in an EndoGRO ${ }^{\mathrm{TM}}$-MV-VEGF Complete Media Kit (EMD Millipore). Cells were seeded at a density of 5,000 cells/well into 96-well plates. After 24 hours, cells were treated for a further 24 hours with different concentrations of SiNPs $(0.1-100 \mu \mathrm{g} / \mathrm{mL})$ in triplicate. Control cultures were treated with saline. The effect of SiNPs on cell viability was determined using a CellTiter-Glo ${ }^{\circledR}$ Luminescent Cell Viability Assay (Promega Corporation, Fitchburg, WI, USA), based on quantification of adenosine triphosphate, which signals the presence of metabolically active cells. 
The luminescent signal was measured using the GloMax ${ }^{\circledR}$ Luminometer system (Promega Corporation). Data were presented as proportional viability (\%) by comparing the treated group with the untreated cells, the viability of which is assumed to be $100 \%$.

\section{In vitro effects of SiNPs on the relaxation of isolated small mesenteric artery induced by acetylcholine in vitro}

Male 5-month-old Wistar Kyoto rats were killed with an overdose of a mixture of the anesthetics ketamine (140 mg/kg intramuscularly) and xylazine (40 mg/kg intramuscularly). Isolated third branches of mesenteric arteries were mounted on a wire myograph (Danish Myo Technology, Aarhus, Denmark) to measure isometric tension. Arteries were superfused with warm $\left(37^{\circ} \mathrm{C}\right)$ physiological saline solution of the following composition (mM): $119 \mathrm{NaCl}$, $4.7 \mathrm{KCl}, 1.18 \mathrm{KH}_{2} \mathrm{PO}_{4}, 1.17 \mathrm{MgSO}_{4}, 25 \mathrm{NaHCO}_{3}$, 5.5 glucose, and $1.6 \mathrm{CaCl}_{2}, \mathrm{pH} 7.4$, adjusted with $\mathrm{NaOH}$. After the normalization procedure, arteries were left to equilibrate for 1 hour at $37^{\circ} \mathrm{C}$ before subsequent evaluation. Prior to each experiment the integrity of the endothelium was confirmed by contracting arteries with $4 \mu \mathrm{m}$ phenylephrine followed by $1 \mu \mathrm{m}$ endothelium-dependent vasodilator acetylcholine (Ach). Vessels that failed to produce at least $80 \%$ relaxations were eliminated.

To evaluate the effect of SiNPs on endothelium-dependent relaxation, arteries were contracted with $4 \mu \mathrm{m}$ phenylephrine and then relaxed with Ach in a dose-response manner $(0.1 \mathrm{~nm}-10 \mu \mathrm{m})$ in the absence of and after incubation with SiNPs $(2 \mu \mathrm{g} / \mathrm{mL}, 10 \mu \mathrm{g} / \mathrm{mL}$, and $50 \mu \mathrm{g} / \mathrm{mL})$.

\section{Statistics}

Data were expressed as means \pm standard error of mean, and were analyzed with GraphPad Prism version 4.01 for Windows software (GraphPad Software Inc., La Jolla, CA, USA). Comparisons between the groups were performed by analysis of variance, followed by Bonferroni multiple-range tests. $P$-values $<0.05$ are considered significant.

\section{Results}

\section{Effect of SiNPs on photochemically induced thrombosis in pial venules}

Figure 1 shows that SiNP administration caused a significant shortening of the thrombotic occlusion time in pial venules of mice with $50 \mathrm{~nm}(-24 \%, P<0.01)$ and $500 \mathrm{~nm}(-20 \%$, $P<0.05)$ particles compared with the control group.

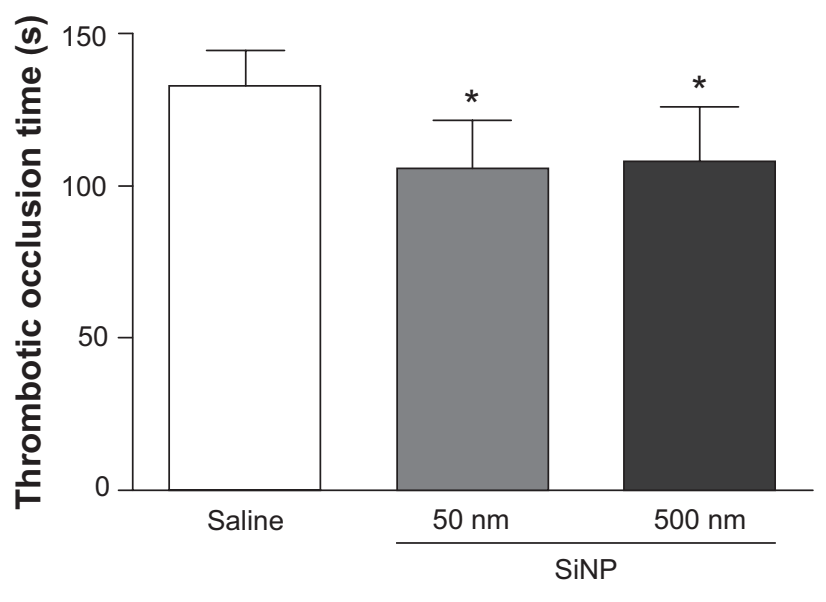

Figure I Thrombotic occlusion time in pial venules 24 hours after the administration of either $50 \mathrm{~nm}$ or $500 \mathrm{~nm}$ amorphous silica nanoparticles $(0.5 \mathrm{mg} / \mathrm{kg})$ in mice. Notes: $* P<0.01$ compared with the corresponding saline-treated group. Data are mean \pm standard error of mean $(n=8)$.

Abbreviations: s, seconds; SiNP, silica nanoparticle.

\section{Effect of SiNPs on circulating platelet numbers, PAI-I, fibrinogen, and vWF concentrations in plasma}

Figure 2A illustrates that exposure to $50 \mathrm{~nm}$ SiNPs causes a significant decrease in circulating platelets compared with the control group. This effect is also significantly reduced compared with the $500 \mathrm{~nm}$ SiNPs.

The plasma concentration of PAI-1, an endogenous factor of fibrinolysis, was significantly increased following SiNP administration of both $50 \mathrm{~nm}$ and $500 \mathrm{~nm}$ nanoparticles compared with the control group (Figure 2B).

The concentration of fibrinogen, an acute-phase protein that increases in blood viscosity and promotes thrombus formation, was significantly increased after the administration of $50 \mathrm{~nm}$ SiNPs compared with the control group (Figure 2C). This effect is significantly higher compared with the $500 \mathrm{~nm}$ SiNP group (Figure 2C).

Compared with the control group and the $500 \mathrm{~nm}$ SiNP group, the administration of $50 \mathrm{~nm}$ SiNPs caused a significant increase in plasma vWF, known as a factor of the coagulation process and a marker of endothelial perturbation (Figure 2D).

\section{Effect of SiNPs on PT and aPTT}

The PT in mice exposed to either $50 \mathrm{~nm}$ (13.57 \pm 1.51 seconds) or $500 \mathrm{~nm}$ (14.43 \pm 1.82 seconds) particles did not significantly vary in comparison with the value obtained for the control group (13.59 \pm 1.50 seconds). Similarly, neither $50 \mathrm{~nm}$

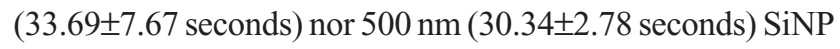
administration significantly affected the aPTT compared with the control group (36.60 18.83 seconds). 
A

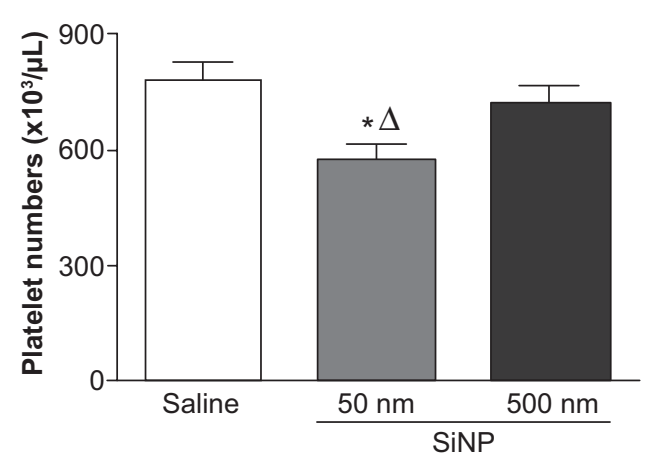

C

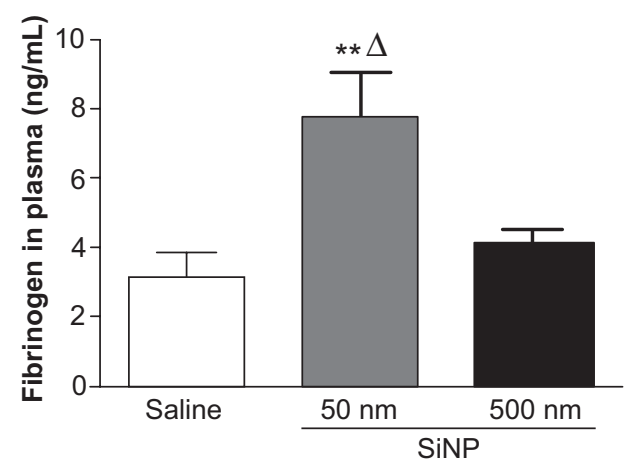

B

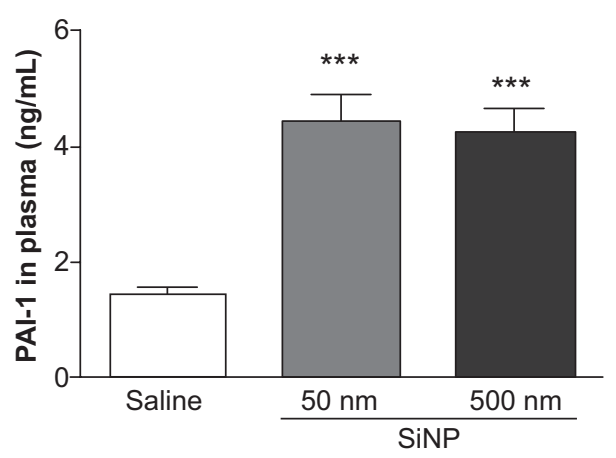

D

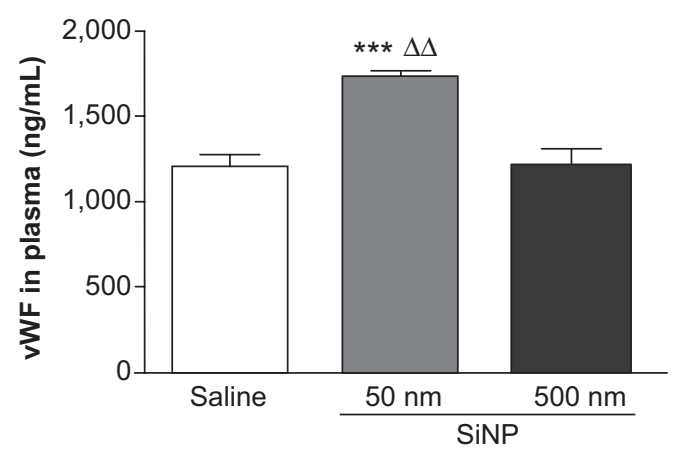

Figure 2 Results 24 hours after the administration of either $50 \mathrm{~nm}$ or $500 \mathrm{~nm}$ amorphous silica nanoparticles $(0.5 \mathrm{mg} / \mathrm{kg})$ in mice.

Notes: Platelet numbers (A) and plasminogen activator inhibitor-I (B), fibrinogen (C), and von Willebrand factor (D) concentrations in plasma, 24 hours after the administration of either $50 \mathrm{~nm}$ or $500 \mathrm{~nm}$ amorphous silica nanoparticles $(0.5 \mathrm{mg} / \mathrm{kg})$ in mice. $* P<0.05$, $* * P<0.005$, and $* * * P<0.000 \mathrm{I}$ compared with the corresponding salinetreated group. ${ }^{\Delta P}<0.05$ and $\triangle \Delta P<0.000$ I compared with the $500 \mathrm{~nm}$ silica nanoparticle-treated group. Data are mean \pm standard error of mean ( $\mathrm{n}=6-8$ ).

Abbreviations: SiNP, silica nanoparticle; PAI-I, plasminogen activator inhibitor-I; vWF, von Willebrand factor.

\section{In vitro effect of SiNPs on platelet aggregation in whole blood in vitro}

Low concentrations of $50 \mathrm{~nm}$ and $500 \mathrm{~nm} \operatorname{SiNPs}(0.2-5 \mu \mathrm{g} / \mathrm{mL}$ blood) caused platelet aggregation in a dose-dependent manner. Concentration-dependent and significant effects were seen on platelet aggregation following the addition of various concentrations of $500 \mathrm{~nm}$ SiNPs. After the addition of different concentrations of $50 \mathrm{~nm} \mathrm{SiNPs,} \mathrm{clear}$ dose-dependent and significant effects of SiNPs on platelet aggregation were observed. Moreover, the effects observed in the $50 \mathrm{~nm}$ SiNP-treated group were statistically significant compared with the same concentration in the $500 \mathrm{~nm}$-treated SiNP group (Figure 3).

\section{Effect of SiNPs on plasma LDH activity}

Figure 4 illustrates the effect of SiNPs on LDH activity, a marker of cytotoxicity, in plasma. Both $50 \mathrm{~nm}$ and $500 \mathrm{~nm}$ SiNP administration induced a significant increase in LDH activity compared with the control group.

\section{Effect of SiNPs on plasma concentrations of TNF $\alpha$ and IL-I $\beta$}

Figure 5 shows the effect of SiNPs on TNF $\alpha$ and IL- $1 \beta$, both markers of inflammation. The concentration of TNF $\alpha$ in plasma was significantly increased after the administration of $50 \mathrm{~nm}$ SiNPs compared with the control group (Figure 5A); administration of $500 \mathrm{~nm}$ SiNPs had no significant effect (Figure 5A).

Figure 5B shows that administration of both $50 \mathrm{~nm}$ and $500 \mathrm{~nm}$ SiNPs caused a significant increase in plasma IL-1 $\beta$ compared with the control group (Figure 5B). The effect observed with $500 \mathrm{~nm}$ SiNPs was higher than that seen with $50 \mathrm{~nm}$ SiNPs.

\section{Effect of SiNPs on plasma levels of 8-isoprostane,TBARS, catalase, and GST}

Figure 6 illustrates the effects of SiNPs on markers of oxidative stress, including the levels of 8-isoprostane (Figure 6A), TBARS (Figure 6B), catalase (Figure 6C), and GST (Figure 6D). None of the markers measured was affected by the administration of either $50 \mathrm{~nm}$ or $500 \mathrm{~nm}$ SiNPs. 


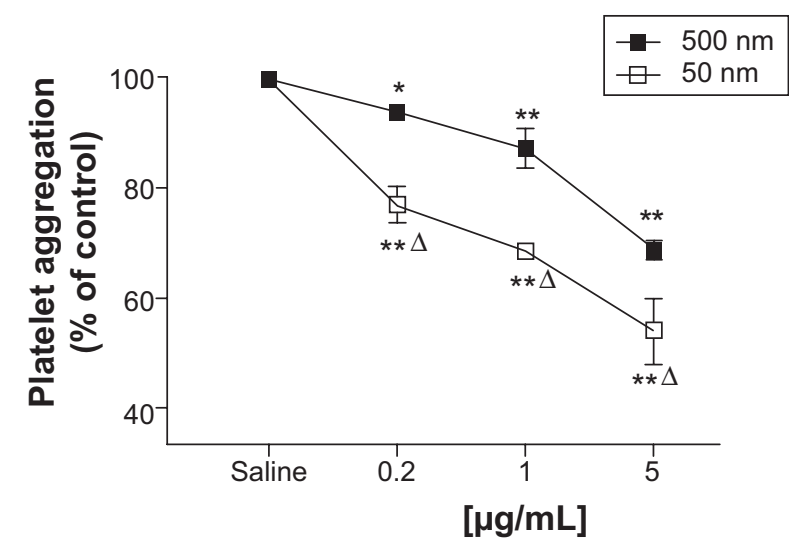

Figure 3 Direct in vitro effect after the administration of either $50 \mathrm{~nm}$ or $500 \mathrm{~nm}$ amorphous silica nanoparticles (SiNPs) on platelet aggregation in whole blood of untreated mice.

Notes: Platelet aggregation in untreated whole blood 3 minutes after the addition of either saline or $50 \mathrm{~nm}$ or $500 \mathrm{~nm} \mathrm{SiNPs}(0.2-5 \mu \mathrm{g} / \mathrm{mL})$ was assessed. The degree of platelet aggregation following SiNP exposure was expressed in percent of control (saline-treated blood). Data are mean \pm standard error of mean $(n=5-6)$. $* P<0.05$ and $* * P<0.00$ I compared with saline-treated blood within the same group. ${ }^{\Delta P}<0.00$ I between $50 \mathrm{~nm}$ and $500 \mathrm{~nm}$ groups for the same given SiNP concentration.

\section{Effect of SiNPs on cellular viability}

As shown in Figure 7, administration of $50 \mathrm{~nm}$ and $500 \mathrm{~nm}$ SiNPs $(0.1-100 \mu \mathrm{g} / \mathrm{mL})$ caused a concentrationdependent decrease in cellular viability of HUVEC cells over 24 hours; $50 \mathrm{~nm}$ SiNPs showed more potency than the $500 \mathrm{~nm}$ SiNPs.

\section{In vitro effect of SiNPs on the relaxation of isolated small mesenteric artery induced by Ach}

Figure 8 illustrates the effect of SiNPs $(2 \mu \mathrm{g} / \mathrm{mL}, 10 \mu \mathrm{g} / \mathrm{mL}$, and $50 \mu \mathrm{g} / \mathrm{mL}$ ) on Ach-induced mesenteric artery relaxations

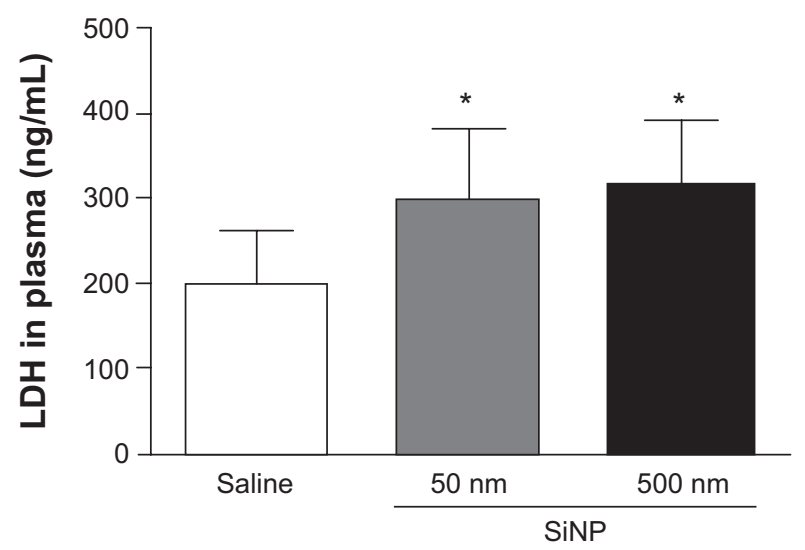

Figure 4 Lactate dehydrogenase activity in plasma 24 hours after the administration of either $50 \mathrm{~nm}$ or $500 \mathrm{~nm}$ amorphous silica nanoparticles $(0.5 \mathrm{mg} / \mathrm{kg})$ in mice. Notes: $* P<0.05$ compared with the corresponding saline-treated group. Data are mean \pm standard error of mean $(n=6-7)$.

Abbreviations: LDH, lactate dehydrogenase; SiNP, silica nanoparticle.

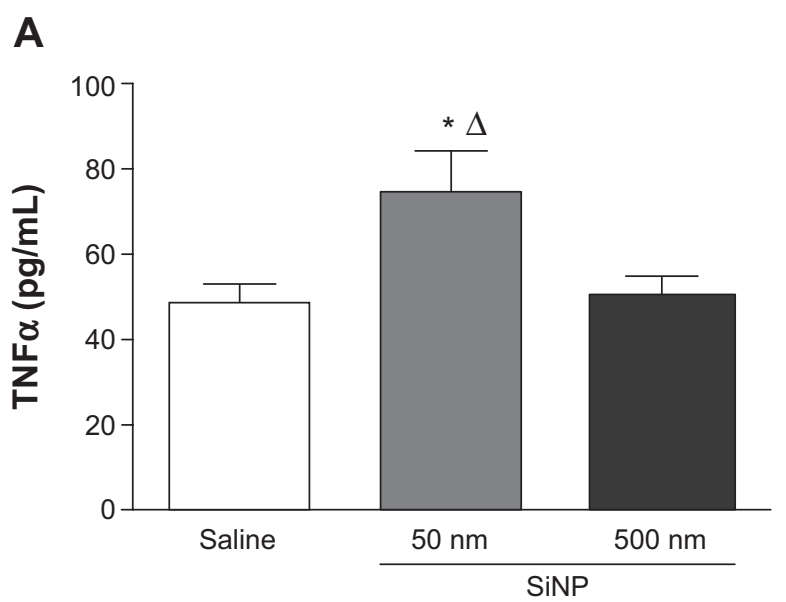

B

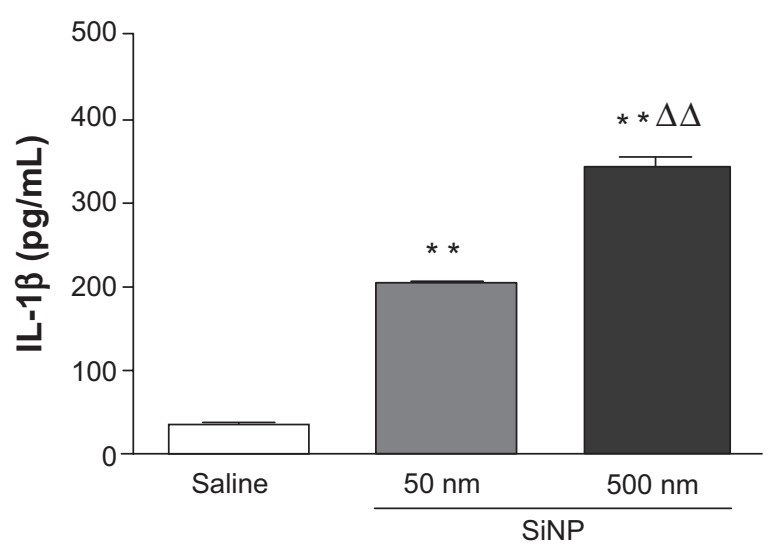

Figure 5 Effect of amorphous silica nanoparticles on plasma concentrations of proinflammatory cytokines.

Notes: Tumor necrosis factor $\alpha(\mathbf{A})$ and interleukin I $\beta(\mathbf{B})$ in plasma, 24 hours after the administration of either $50 \mathrm{~nm}$ or $500 \mathrm{~nm}$ amorphous silica nanoparticles $(0.5 \mathrm{mg} / \mathrm{kg})$ in mice. $* P<0.05$ and $* * P<0.001$ compared with the corresponding saline-treated group. ${ }^{\Delta P}<0.05$ and $\Delta \Delta P<0.000 \mathrm{I}$ between $50 \mathrm{~nm}$ and $500 \mathrm{~nm}$ silica nanoparticle-treated groups. Data are mean \pm standard error of mean $(n=6-8)$.

Abbreviations: TNF $\alpha$, tumor necrosis factor $\alpha$; SiNP, silica nanoparticle; IL-I $\beta$, interleukin I $\beta$.

$(0.1 \mathrm{~nm}-10 \mu \mathrm{m})$. A significant effect was observed only at the concentration of $50 \mu \mathrm{g} / \mathrm{mL}$, where both $50 \mathrm{~nm}$ and $500 \mathrm{~nm}$ SiNPs caused a significant reduction in the relaxation of the rat small mesenteric arteries from $93.4 \% \pm 1.4 \%$ to $62.0 \% \pm 12.0 \%$ (50 nm; Figure $8 \mathrm{~A}$ ) and $93 \% \pm 2.7 \%$ to $64 \% \pm 6.5 \%$ (500 nm; Figure $8 \mathrm{~B}$ ) at the $0.1 \mu \mathrm{m}$ Ach concentration.

\section{Discussion}

In the present study, we wanted to investigate whether and to what extent SiNPs cause vascular alteration, systemic inflammation, and oxidative stress at 24 hours post exposure. To this end, we used IP administration, because we wanted to mimic the effect of injected nanoparticles as it may occur with medical applications. ${ }^{1,3}$ Moreover, it has been demonstrated that inhaled particles translocate from the lungs into the systemic circulation. ${ }^{5-8}$ The in vivo exposure dose used in 
A

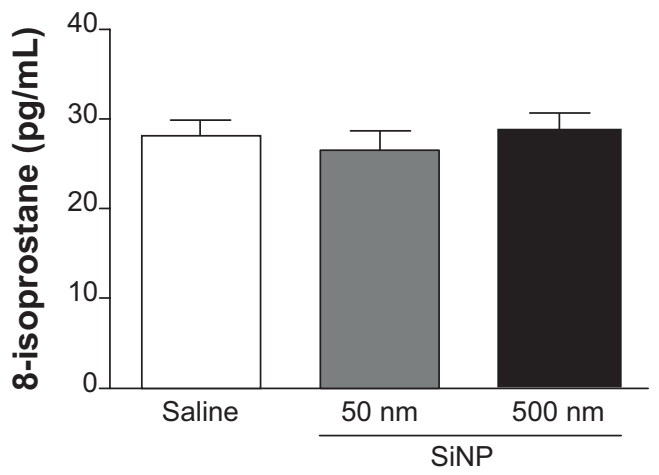

C

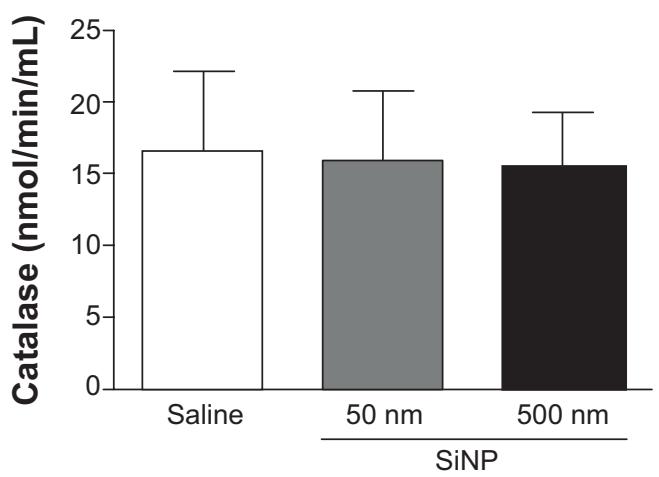

B

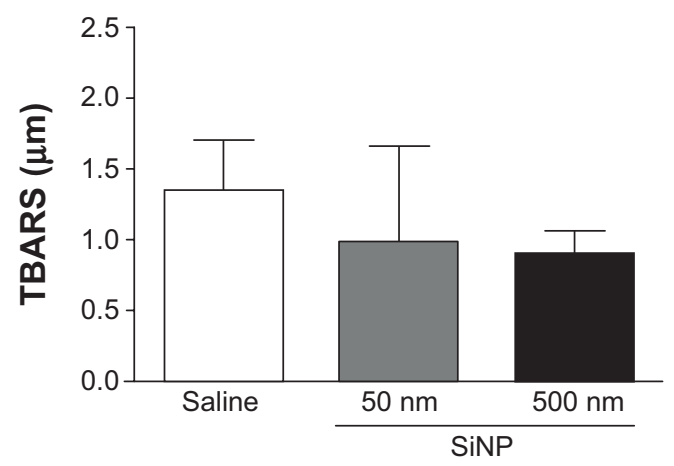

D

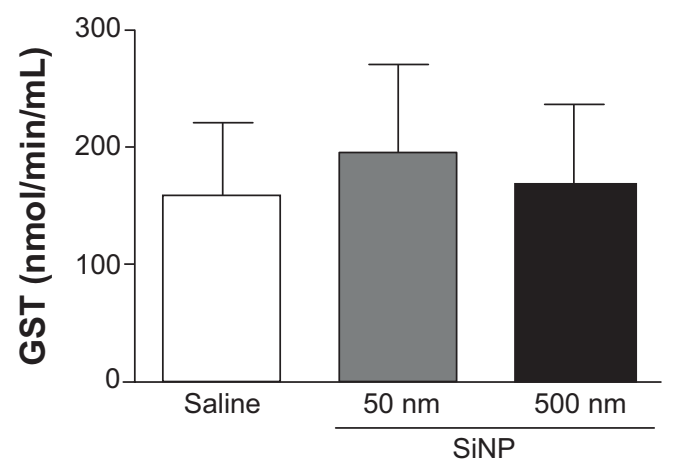

Figure 6 Effect of amorphous silica nanoparticles markers of oxidative stress in plasma.

Notes: 8-isoprostane $(\mathbf{A})$ thiobarbituric acid reactive substances $(\mathbf{B})$ catalase $(\mathbf{C})$ and glutathione S-transferase (D) levels in plasma, 24 hours after the administration of either $50 \mathrm{~nm}$ or $500 \mathrm{~nm}$ amorphous silica nanoparticles $(0.5 \mathrm{mg} / \mathrm{kg})$ in mice. Data are mean \pm standard error of mean $(\mathrm{n}=7-8)$.

Abbreviations: SiNP, silica nanoparticles; TBARS, thiobarbituric acid reactive substances; GST, glutathione S-transferase; min, minute.

the present study reflected IP doses used in previous studies of nanoparticles. ${ }^{25,26}$ Moreover, it represents about $10 \%$ of the dose of nanoparticles intratracheally instilled in experimental animals. ${ }^{27-30}$

In the present study, we have assessed the effect of SiNPs on coagulation events by measuring a set of relevant indices: ie, thrombosis assessment in pial venules in vivo; platelet numbers and aggregation in vitro; and measurement of circulating fibrinogen, PAI-1, and soluble vWF. It has been recently demonstrated that in vitro exposure of human platelets to amorphous SiNPs causes platelet aggregation and high nitroxidative/oxidative stress. ${ }^{15}$ However, as far
A

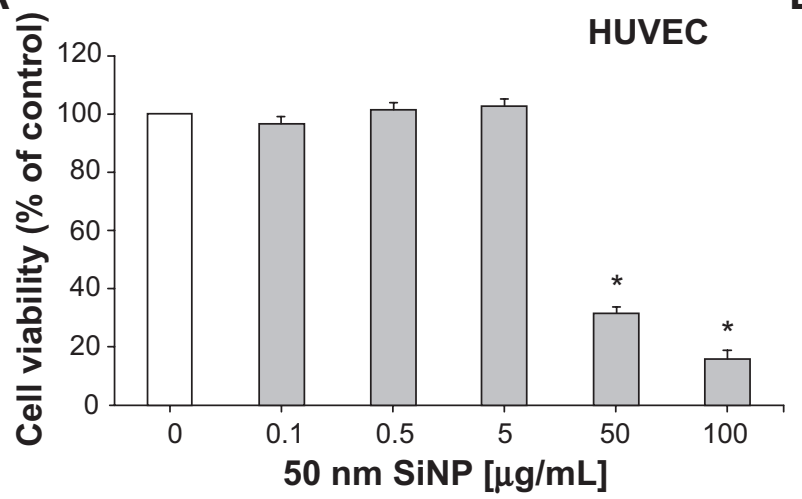

B

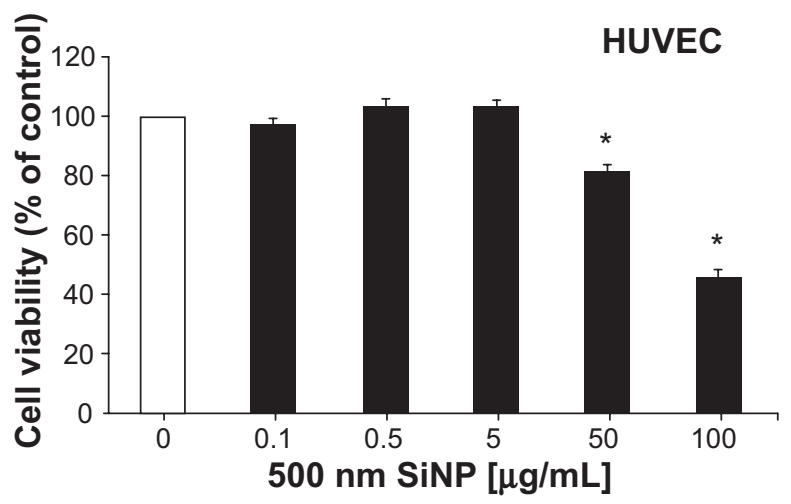

Figure 7 Inhibition of cellular viability by amorphous silica nanoparticles.

Notes: Inhibition of cellular viability by $50 \mathrm{~nm}(\mathbf{A})$ and $500 \mathrm{~nm}(\mathbf{B})$ amorphous silica nanoparticles. Exponentially growing human umbilical vein endothelial cells were treated with either saline or various concentrations $(0.1-100 \mu \mathrm{g} / \mathrm{mL})$ of $50 \mathrm{~nm}$ or $500 \mathrm{~nm}$ silica nanoparticles. Viable cells were assayed as described in materials and methods. All experiments were repeated three times. Data are mean \pm standard error of mean. $* P<0.001$ compared with the corresponding control-treated group. Abbreviations: HUVEC, human umbilical vein endothelial cells; SiNP, silica nanoparticle. 
A

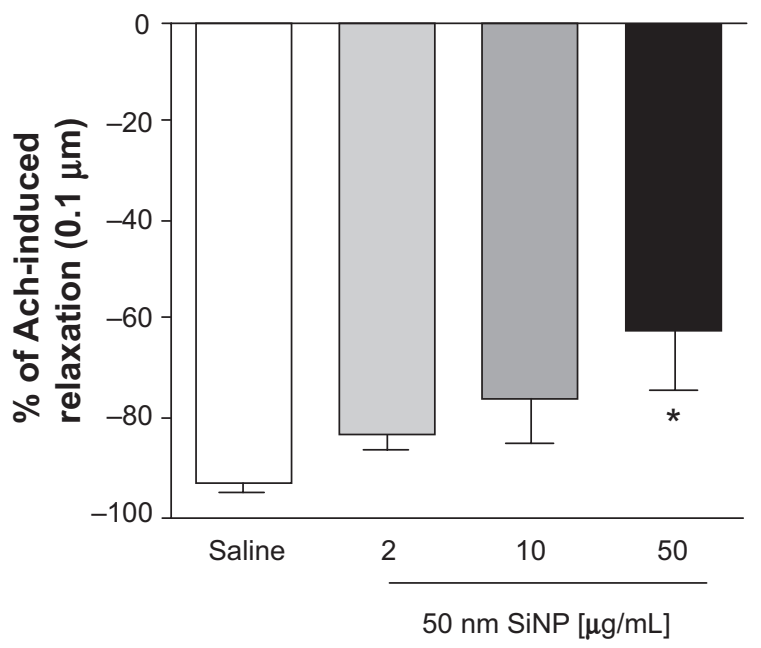

B

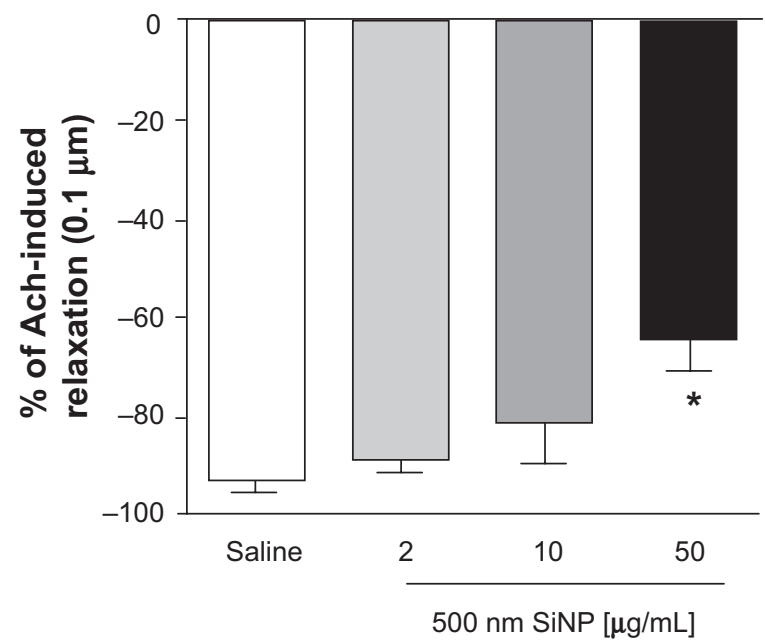

Figure 8 Relaxation of small mesenteric arteries of rats.

Notes: Relaxation of small mesenteric arteries of rats caused by $0.1 \mu \mathrm{m}$ acetylcholine after incubation with either saline (control) or various concentrations $(2-50 \mu g / \mathrm{mL})$ of either $50 \mathrm{~nm}$ (A) or $500 \mathrm{~nm}$ (B) amorphous silica nanoparticles. Data are mean \pm standard error of mean of \% change ( $=4$ ). $* P<0.05$ compared with the corresponding saline-treated group.

Abbreviations: Ach, acetylcholine; SiNP, silica nanoparticle.

as we are aware, no study has reported the possible in vivo thrombotic effects of amorphous SiNPs. Our data show that IP administration of SiNPs causes prothrombotic events in pial venules. Our findings corroborate recent studies that reported that exposure to either polystyrene nanoparticles ${ }^{31}$ or diesel exhaust particles (DEP) induces thrombosis..$^{19,30,32}$ Along with the prothrombotic effect of SiNPs, we found a significant decrease in platelet numbers in $50 \mathrm{~nm}$ SiNP-exposed mice; this is indicative of platelet activation in vivo. A decrease in platelet numbers following exposure to particles has been previously reported from experimental and clinical studies. ${ }^{19,33}$

We found a significant increase of circulating PAI-1 following the administration of $50 \mathrm{~nm}$ and $500 \mathrm{~nm}$ SiNPs. PAI-1 is the most potent endogenous inhibitor of fibrinolysis and is involved in the pathogenesis of several cardiovascular diseases. ${ }^{34,35}$ An increase of PAI-1 has been observed following exposure to either $\mathrm{DEP}^{36}$ or carbon nanotubes. ${ }^{37}$ In conjunction with the fibrinolytic factor PAI-1, in the present study we measured the coagulation factor fibrinogen and found a significant increase following exposure to $50 \mathrm{~nm}$ SiNPs. Our data suggest an impairment of the fibrinolytic system and activation of blood coagulation following SiNP exposure. We also found an increase in $\mathrm{vWF}$ in mice treated with $50 \mathrm{~nm}$ SiNPs. vWF reflects endothelial cell release and vascular reactivity. Moreover, vWF can mediate platelet adhesion to damaged endothelium, which could explain, at least partly, the observed in vivo prothrombotic effects of SiNPs. Elevated levels of vWF were observed in association with increased concentrations of particulate matter in patients with coronary heart disease ${ }^{38}$ and mice exposed to nanoparticles. ${ }^{39}$

Because the thrombosis measured in vivo in our model depends mainly on the intensity of the vascular lesion and subsequent platelet recruitment and aggregation, we aimed at assessing the direct effect of SiNPs on platelet aggregation in whole blood in vitro. Our observations confirmed the occurrence of platelet aggregation following the addition of SiNPs. Interestingly, the effects observed with all the tested concentrations of SiNPs $(0.2-5 \mu \mathrm{g} / \mathrm{mL})$ were significantly more pronounced with $50 \mathrm{~nm}$ compared with $500 \mathrm{~nm}$ SiNPs, suggesting a size effect of the nanoparticles. Transmission electron microscopy study showed that SiNPs interacted with the platelet surface membrane, then internalized and distributed within the platelet cytoplasm in vitro. ${ }^{15} \mathrm{~A}$ dosedependent cytotoxicity of SiNPs $(16-335 \mathrm{~nm})$ in a human endothelial cell line has been reported. ${ }^{9}$ The toxicity of the particles was strongly related to their size. Indeed, smaller particles showed significantly higher toxicity and also affected the exposed cells faster. ${ }^{9}$ Therefore, the particle sizes of SiNPs are affecting their biological effects.

The present data show that SiNP exposure causes a significant increase in plasma LDH activity. This increase is suggestive of cytolysis, and has been described following exposure to nanoparticles in vivo ${ }^{27}$ and in vitro. ${ }^{40}$

We have recently reported the occurrence of oxidative stress in the DEP-induced acute thrombotic tendency in pial venules and activation of circulating blood platelets in mice. ${ }^{19}$ Moreover, we showed that pretreatment with 
the antioxidant cysteine prodrug L-2-oxothiazolidine4-carboxylic acid prevented DEP-induced oxidative stress and the resulting thrombotic complications. ${ }^{19}$ To assess further the mechanism underlying the thrombotic effects of SiNPs, we have measured various markers of oxidative stress including 8-isoprostane, TBARS, catalase, and GST. Our data show that SiNP administration did not affect any of the oxidative stress markers that we measured. This finding was unexpected in view of the fact that we previously reported the contribution of oxidative stress in the effects of $\mathrm{DEP}^{19}$ or $\mathrm{TiO}_{2}$ nanoparticulates. ${ }^{27}$ Moreover, recent studies reported the occurrence of oxidative stress following repeated intratracheal instillation of SiNPs $(2-10 \mathrm{mg} / \mathrm{kg})^{17}$ and in vitro in human endothelial cells. ${ }^{41}$ The lack of effect of SiNPs on markers of oxidative stress at the studied time point (24 hours) does not, however, exclude the possible occurrence of oxidative stress at an earlier time point. ${ }^{20}$ Additional studies are required to clarify this point.

On the other hand, the measurement of proinflammatory cytokine showed a significant increase of TNF $\alpha$ after the administration of $50 \mathrm{~nm}$ SiNPs and IL-1 $\beta$ following the exposure to both $50 \mathrm{~nm}$ and $500 \mathrm{~nm}$ SiNPs. This finding confirms the occurrence of systemic inflammation, which can explain the thrombotic effects of SiNPs., ${ }^{42}$ In vitro release of IL-1 $\beta$ and TNF $\alpha$ has been reported following exposure to amorphous SiNPs. ${ }^{43,44}$

To gain more insight into the effect of SiNPs on vascular homeostasis, we tested the direct effects of SiNPs on HUVEC cells and endothelium-dependent relaxation in the small mesenteric arteries of rats. Our data show a reduced cellular viability, in a concentration-dependent manner, 24 hours following the exposure to SiNPs. A significant decrease in cellular viability was observed at concentrations of $50 \mu \mathrm{g} / \mathrm{mL}$ and $100 \mu \mathrm{g} / \mathrm{mL}$ for both $50 \mathrm{~nm}$ and $500 \mathrm{~nm}$ SiNPs. However, a more marked effect was observed with $50 \mathrm{~nm}$ than $500 \mathrm{~nm}$ SiNPs. It has been recently demonstrated that amorphous SiNPs penetrate the plasma membrane of endothelial cells and cause cytotoxicity, and that this effect was inversely proportional to nanoparticle size. ${ }^{14}$ We also tested the effects of SiNPs on endotheliumdependent relaxation of arteries induced by Ach, and found that both sizes of nanoparticles at $50 \mu \mathrm{g} / \mathrm{mL}$ reduced Ach-induced relaxations of mesenteric arteries in vitro. Epidemiological evidence has linked impaired endothelium-dependent vascular reactivity with cardiovascular diseases, ${ }^{45}$ and a close relationship has been reported between cardiovascular risk increase and impairment of endothelial function and vascular activity related to particulate air pollution. ${ }^{46}$ It has been shown that $\mathrm{TiO}_{2}$ nanoparticle exposure significantly impairs endothelium-dependent vasodilation in the subepicardial arterioles of rats. ${ }^{47}$

In summary, we showed that 24 hours after their administration, amorphous SiNPs cause prothrombotic effects in vivo and in vitro, and increases in plasma concentrations of fibrinogen, PAI-1, vWF, and proinflammatory cytokines, including TNF $\alpha$ and IL-1 $\beta$. Markers of oxidative stress comprising 8-isoprostane, TBARS, catalase, and GST were not affected by SiNPs. Moreover, we showed that SiNPs induce HUVEC cytotoxicity and reduce endothelium-dependent relaxation of small mesenteric arteries in vitro. Overall, the observed adverse effects were size-dependent since more marked effects were recorded with the $50 \mathrm{~nm}$ in comparison with the $500 \mathrm{~nm}$ SiNPs. ${ }^{4}$ This can be ascribed to the high surface-area-to-volume ratio, which decreases in the opposite direction to size; this favors biological interactions and, consequently, causes more vascular and systemic toxicity. Our findings provide plausible elucidation that SiNPs are injurious to vascular homeostasis.

\section{Acknowledgments}

The authors wish to thank Mrs Khouloud Arafat, Department of Pharmacology, College of Medicine and Health Sciences, United Arab Emirates University and Ms Intisar Al-Lawati, Department of Physiology, College of Medicine and Health Sciences, Sultan Qaboos University for their excellent technical help.

This work was supported by funds of the College of Medicine and Health Sciences grant, United Arab Emirates University, and a National Research Foundation - United Arab Emirates University grant.

The experiments related to cellular viability were supported by the Terry Fox Fund for Cancer Research to Dr Samir Attoub.

The authors wish to thank Professor Gerald Blunden (University of Portsmouth, UK) for critically reading the manuscript.

\section{Disclosure}

The authors report no conflicts of interest in this work.

\section{References}

1. Napierska D, Thomassen LC, Lison D, Martens JA, Hoet PH. The nanosilica hazard: another variable entity. Part Fibre Toxicol. 2010; 7(1):39.

2. Calvert GM, Rice FL, Boiano JM, Sheehy JW, Sanderson WT. Occupational silica exposure and risk of various diseases: an analysis using death certificates from 27 states of the United States. Occup Environ Med. 2003;60(2):122-129.

3. Madl AK, Pinkerton KE. Health effects of inhaled engineered and incidental nanoparticles. Crit Rev Toxicol. 2009;39(8):629-658. 
4. Nemmar A, Holme JA, Rosas I, Schwarze PE, Alfaro-Moreno E. Recent advances in particulate matter and nanoparticle toxicology: a review of the in vivo and in vitro studies. Biomed Res Int. 2013;2013:279371.

5. Nemmar A, Hoet PH, Vanquickenborne B, et al. Passage of inhaled particles into the blood circulation in humans. Circulation. 2002; 105(4):411-414.

6. Nemmar A, Vanbilloen H, Hoylaerts MF, Hoet PH, Verbruggen A, Nemery B. Passage of intratracheally instilled ultrafine particles from the lung into the systemic circulation in hamster. Am J Respir Crit Care Med. 2001;164(9):1665-1668.

7. Péry AR, Brochot C, Hoet PH, Nemmar A, Bois FY. Development of a physiologically based kinetic model for 99m-technetiumlabelled carbon nanoparticles inhaled by humans. Inhal Toxicol. 2009;21(13):1099-1107.

8. Oberdörster G, Sharp Z, Atudorei V, et al. Extrapulmonary translocation of ultrafine carbon particle following whole-body inhalation exposure of rats. J Toxicol Environ Health A. 2002;65(20):1531-1543.

9. Napierska D, Thomassen LC, Rabolli V, et al. Size-dependent cytotoxicity of monodisperse silica nanoparticles in human endothelial cells. Small. 2009;5(7):846-853.

10. Lison D, Thomassen LC, Rabolli V, et al. Nominal and effective dosimetry of silica nanoparticles in cytotoxicity assays. Toxicol Sci. 2008; 104(1):155-162.

11. Kasper J, Hermanns MI, Bantz C, et al. Inflammatory and cytotoxic responses of an alveolar-capillary coculture model to silica nanoparticles: comparison with conventional monocultures. Part Fibre Toxicol. 2011;8(1):6.

12. Peters K, Unger RE, Kirkpatrick CJ, Gatti AM, Monari E. Effects of nano-scaled particles on endothelial cell function in vitro: studies on viability, proliferation and inflammation. J Mater Sci Mater Med. 2004;15(4):321-325.

13. Napierska D, Quarck R, Thomassen LC, et al. Amorphous silica nanoparticles promote monocyte adhesion to human endothelial cells: size-dependent effect. Small. 2013;9(3):430-438.

14. Corbalan JJ, Medina C, Jacoby A, Malinski T, Radomski MW. Amorphous silica nanoparticles trigger nitric oxide/peroxynitrite imbalance in human endothelial cells: inflammatory and cytotoxic effects. Int $J$ Nanomedicine. 2011;6:2821-2835.

15. Corbalan JJ, Medina C, Jacoby A, Malinski T, Radomski MW. Amorphous silica nanoparticles aggregate human platelets: potential implications for vascular homeostasis. Int J Nanomedicine. 2012;7:631-639.

16. Liu X, Xue Y, Ding T, Sun J. Enhancement of proinflammatory and procoagulant responses to silica particles by monocyte-endothelial cell interactions. Part Fibre Toxicol. 2012;9:36.

17. Du Z, Zhao D, Jing L, et al. Cardiovascular toxicity of different sizes amorphous silica nanoparticles in rats after intratracheal instillation. Cardiovasc Toxicol. 2013;13(3):194-207.

18. Nemmar A, Nemery B, Hoet PHM, Van Rooijen N, Hoylaerts MF. Silica particles enhance peripheral thrombosis: key role of lung macrophage-neutrophil cross-talk. Am J Respir Crit Care Med. 2005;171(8):872-879.

19. Nemmar A, Al-Salam S, Dhanasekaran S, Sudhadevi M, Ali BH. Pulmonary exposure to diesel exhaust particles promotes cerebral microvessel thrombosis: protective effect of a cysteine prodrug 1-2-oxothiazolidine4-carboxylic acid. Toxicology. 2009;263(2-3):84-92.

20. Nemmar A, Al-Salam S, Zia S, et al. Contrasting actions of diesel exhaust particles on the pulmonary and cardiovascular systems and the effects of thymoquinone. Br J Pharmacol. 2011;164(7): 1871-1882.

21. Nemmar A, Al-Salam S, Zia S, Dhanasekaran S, Shudadevi M, Ali BH. Time-course effects of systemically administered diesel exhaust particles in rats. Toxicol Lett. 2010;194(3):58-65.

22. Nemmar A, Zia S, Subramaniyan D, Fahim MA, Ali BH. Exacerbation of thrombotic events by diesel exhaust particle in mouse model of hypertension. Toxicology. 2011;285(1-2):39-45.

23. Nemmar A, Yuvaraju P, Beegam S, John A, Raza H, Ali BH. Cardiovascular effects of nose-only water-pipe smoking exposure in mice. Am J Physiol Heart Circ Physiol. 2013;305(5):H740-H746.
24. Nemmar A, Melghit K, Ali BH. The acute proinflammatory and prothrombotic effects of pulmonary exposure to rutile $\mathrm{TiO} 2$ nanorods in rats. Exp Biol Med (Maywood). 2008;233(5):610-619.

25. Folkmann JK, Risom L, Hansen CS, Loft S, Møller P. Oxidatively damaged DNA and inflammation in the liver of dyslipidemic ApoE-/- mice exposed to diesel exhaust particles. Toxicology. 2007; 237(1-3):134-144.

26. Vesterdal LK, Folkmann JK, Jacobsen NR, et al. Modest vasomotor dysfunction induced by low doses of $\mathrm{C} 60$ fullerenes in apolipoprotein E knockout mice with different degree of atherosclerosis. Part Fibre Toxicol. 2009;6:5.

27. Nemmar A, Melghit K, Al-Salam S, et al. Acute respiratory and systemic toxicity of pulmonary exposure to rutile $\mathrm{Fe}$-doped $\mathrm{TiO}(2)$ nanorods. Toxicology. 2011;279(1-3):167-175.

28. Warheit DB, Webb TR, Reed KL, Frerichs S, Sayes CM. Pulmonary toxicity study in rats with three forms of ultrafine-TiO2 particles: differential responses related to surface properties. Toxicology. 2007;230(1):90-104.

29. Warheit DB, Webb TR, Sayes CM, Colvin VL, Reed KL. Pulmonary instillation studies with nanoscale $\mathrm{TiO} 2$ rods and dots in rats: toxicity is not dependent upon particle size and surface area. Toxicol Sci. 2006;91(1):227-236.

30. Nemmar A, Hoet PH, Dinsdale D, Vermylen J, Hoylaerts MF, Nemery B. Diesel exhaust particles in lung acutely enhance experimental peripheral thrombosis. Circulation. 2003;107(8):1202-1208.

31. Nemmar A, Hoylaerts M, Hoet PH, Vermylen J, Nemery B. Size effect of intratracheally instilled ultrafine particles on pulmonary inflammation and vascular thrombosis. Toxicol Appl Pharmacol. 2003; 186(1):38-45.

32. Radomski A, Jurasz P, Alonso-Escolano D, et al. Nanoparticleinduced platelet aggregation and vascular thrombosis. BrJ Pharmacol. 2005;146(6):882-893.

33. Rückerl R, Phipps RP, Schneider A, et al. Ultrafine particles and platelet activation in patients with coronary heart disease - results from a prospective panel study. Part Fibre Toxicol. 2007;4:1.

34. Thögersen AM, Jansson JH, Boman K, et al. High plasminogen activator inhibitor and tissue plasminogen activator levels in plasma precede a first acute myocardial infarction in both men and women: evidence for the fibrinolytic system as an independent primary risk factor. Circulation. 1998;98(21):2241-2247.

35. Cesari M, Pahor M, Incalzi RA. Plasminogen activator inhibitor-1 (PAI-1): a key factor linking fibrinolysis and age-related subclinical and clinical conditions. Cardiovasc Ther. 2010;28(5):e72-e91.

36. Nemmar A, Subramaniyan D, Ali BH. Protective effect of curcumin on pulmonary and cardiovascular effects induced by repeated exposure to diesel exhaust particles in mice. PLoS One. 2012;7(6):e39554.

37. Erdely A, Hulderman T, Salmen R, et al. Cross-talk between lung and systemic circulation during carbon nanotube respiratory exposure. Potential biomarkers. Nano Lett. 2009;9:36-43.

38. Rückerl R, Ibald-Mulli A, Koenig W, et al. Air pollution and markers of inflammation and coagulation in patients with coronary heart disease. Am J Respir Crit Care Med. 2006;173(4):432-441.

39. Khandoga A, Stampfl A, Takenaka S, et al. Ultrafine particles exert prothrombotic but not inflammatory effects on the hepatic microcirculation in healthy mice in vivo. Circulation. 2004;109(10):1320-1325.

40. Boland S, Baeza-Squiban A, Fournier T, et al. Diesel exhaust particles are taken up by human airway epithelial cells in vitro and alter cytokine production. Am J Physiol. 1999;276(4 Pt 1):L604-L613.

41. Napierska D, Rabolli V, Thomassen LC, et al. Oxidative stress induced by pure and iron-doped amorphous silica nanoparticles in subtoxic conditions. Chem Res Toxicol. 2012;25(4):828-837.

42. Vermylen J, Nemmar A, Nemery B, Hoylaerts MF. Ambient air pollution and acute myocardial infarction. J Thromb Haemost. 2005; 3(9):1955-1961.

43. Napierska D, Thomassen LC, Vanaudenaerde B, et al. Cytokine production by co-cultures exposed to monodisperse amorphous silica nanoparticles: the role of size and surface area. Toxicol Lett. 2012;211(2):98-104. 
44. Sandberg WJ, Låg M, Holme JA, et al. Comparison of non-crystalline silica nanoparticles in IL-1beta release from macrophages. Part Fibre Toxicol. 2012;9:32.

45. Suwaidi JA, Hamasaki S, Higano ST, Nishimura RA, Holmes DR Jr, Lerman A. Long-term follow-up of patients with mild coronary artery disease and endothelial dysfunction. Circulation. 2000; 101(9):948-954.

46. Chuang KJ, Chan CC, Su TC, Lee CT, Tang CS. The effect of urban air pollution on inflammation, oxidative stress, coagulation, and autonomic dysfunction in young adults. Am J Respir Crit Care Med. 2007;176(4):370-376.
47. LeBlanc AJ, Cumpston JL, Chen BT, Frazer D, Castranova V, Nurkiewicz TR. Nanoparticle inhalation impairs endotheliumdependent vasodilation in subepicardial arterioles. $J$ Toxicol Environ Health A. 2009;72(24):1576-1584.
International Journal of Nanomedicine

\section{Publish your work in this journal}

The International Journal of Nanomedicine is an international, peerreviewed journal focusing on the application of nanotechnology in diagnostics, therapeutics, and drug delivery systems throughout the biomedical field. This journal is indexed on PubMed Central, MedLine, CAS, SciSearch $®$, Current Contents $® /$ Clinical Medicine,

\section{Dovepress}

Journal Citation Reports/Science Edition, EMBase, Scopus and the Elsevier Bibliographic databases. The manuscript management system is completely online and includes a very quick and fair peer-review system, which is all easy to use. Visit http://www.dovepress.com/ testimonials.php to read real quotes from published authors.

Submit your manuscript here: http://www.dovepress.com/international-journal-of-nanomedicine-journal 